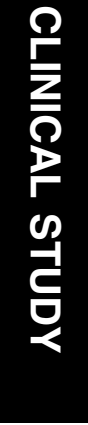

${ }^{1}$ Department of Ophthalmology, Taipei

Veterans General Hospital, Taipei, Taiwan, Republic of China

${ }^{2}$ Department of Ophthalmology, National Yang-Ming University School of Medicine, Taipei, Taiwan, Republic of China

${ }^{3}$ Department of Ophthalmology, Taipei Medical University, Taipei, Taiwan, Republic of China

${ }^{4}$ Department of Anesthesiology, Taipei Veterans General Hospital, Taipei, Taiwan, Republic of China

${ }^{5}$ Department of Ophthalmology, Shuang-Ho Hospital, Taipei, Taiwan, Republic of China

Correspondence: S-M Lee, Department of Ophthalmology, Taipei Veterans General Hospital,

National Yang-Ming

University,

201 Sec. 2, Shih-Pai Road, Taipei 11217,

Taiwan,

Republic of China

Tel: + 88622875 7325;

Fax: + 886228761351

E-mail: smlee@

vghtpe.gov.tw

Received: 29 September 2008

Accepted in revised form:

5 March 2009

Published online: 3 April 2009

\section{Long-term visual outcomes of laser- treated threshold retinopathy of prematurity: a study of refractive status at 7 years}

\author{
Abstract \\ Purpose To assess the long-term visual \\ outcomes and refractive status in patients with \\ diode laser-treated threshold retinopathy of \\ prematurity (ROP), and to investigate the \\ causes of impaired visual function.
}

Method A total of 60 eyes of 30 consecutive patients with diode laser-treated threshold ROP were recalled for assessment at the age of 7 years or more.

Results There were 38 eyes $(65.5 \%)$ achieving $6 / 12$ or better vision, however, an unfavourable visual outcome $(6 / 60$ or worse) occurred in four eyes $(6.9 \%)$. One eye $(1.7 \%)$ had unfavourable structural outcome. Of these 60 laser-treated eyes, 46 eyes $(77.0 \%)$ were myopic, the overall mean spherical equivalent was $-3.87 \mathrm{D}$. Anisometropia ( $\geqslant 1.5 \mathrm{D})$ was also noted in 14 patients $(46.7 \%)$. Strabismus was present in nine patients $(30.0 \%)$. Perinatal neurological events of intraventricular haemorrhage (IVH) were identified in eight children (26.7\%), periventricular leucomalacia (PVL) in eight children $(26.7 \%)$, and cerebral palsy (CP) in four children (13.3\%). There was a statistically significant association of the presence of strabismus with PVL $(P=0.002)$. The presence of anisometropia was a significant risk factor associated with poor visual outcome of $6 / 15$ or worse in laser-treated ROP $(P=0.002)$.

Conclusion The majority of patients with diode laser-treated threshold ROP had favourable anatomical and visual outcomes. However, anisometropia, advanced refractive error, strabismus, and perinatal neurological events remain important causes of impaired visual function. Long-term follow-up is very
C-S Yang ${ }^{1,2,3}$, A-G Wang 1,2,3, C-S Sung ${ }^{2,4}$

W-M Hsu ${ }^{3,5}$, F-L Lee ${ }^{1,2}$ and S-M Lee Lee $^{1,2}$ important for early detection and timely treatment of these ocular morbidities.

Eye (2010) 24, 14-20; doi:10.1038/eye.2009.63; published online 3 April 2009

Keywords: diode laser; retinopathy of prematurity; visual outcome

Introduction

The sequelae of retinopathy of prematurity (ROP) is an important cause of infant blindness and visual disability in the world. ${ }^{1}$ The 10 -year outcome study of the Cryotherapy for Retinopathy of Prematurity Cooperative Group (CRYO-ROP) has demonstrated the long-term benefit of cryotherapy on eyes with threshold ROP. ${ }^{2}$ Recently, laser photocoagulation therapy has almost replaced cryotherapy for retinal ablation of active ROP. Laser therapy is reported to be less traumatic with better structural and functional outcomes compared with eyes treated with cryotherapy in threshold ROP. ${ }^{3-5}$ Moreover, the study of the Early Treatment for ROP Cooperative Group (ETROP) revealed earlier treatment improved grating visual acuity and retinal structural outcomes for subthreshold ROP at the age of 9 months as compared with conventional threshold ROP treatment. ${ }^{6}$

The visual outcome of premature infants with regressed ROP is attributed to both structural and functional outcomes. Myopia, strabismus, anisometropia, astigmatism, and amblyopia are common problems in eyes with regressed ROP. Therefore, the importance of long-term followup of these children cannot be overemphasized. However, few studies with recent data 
concerning the long-term functional outcomes after laser therapy and subsequent refractive status of threshold ROP in Asia are available. ${ }^{7}$

The purpose of this study is to present our experience about the long-term visual outcomes of premature infants who received diode laser photocoagulation for threshold ROP during a 7-year follow-up. In this study, we highlight the refractive status in these patients.

Additionally, we also investigate the causes of impaired visual function in laser-treated threshold ROP.

\section{Patients and methods}

The study protocol was approved by the Institutional Review Board of Taipei Veterans General Hospital. From January 1997 to December 2000, premature infants who weighed less than $2000 \mathrm{~g}$ of birth body weight or were less than 34 weeks of gestational age were screened for ROP in the neonatal newborn room or intensive care unit at Taipei Veterans General Hospital by a single ophthalmologist (CY).

At the first ophthalmic examination, the eyes of highrisk premature infants were screened at postnatal age of 4-6 weeks under indirect ophthalmoscope. ${ }^{8,9}$ The stage and severity of ROP was classified according to the International Classification of ROP (ICROP). ${ }^{10}$ Follow-up retinal examination was performed every 1-2 weeks until ROP regression, complete vasculogenesis of retina, or development of threshold ROP. Threshold disease of ROP was defined as $\geqslant 5$ contiguous or 8 cumulative clock-hours of extraretinal neovascularization stage 3 ROP associated with plus disease within zones I or II. Plus disease represented the dilatation and tortuosity of retinal blood vessels in the posterior pole. Rush disease was defined as ROP in zone 1 with plus disease, which progressed rapidly within days. Infants with threshold disease received retinal ablation laser photocoagulation therapy within $72 \mathrm{~h}$ of diagnosis.

Data were retrospectively collected from the medical records. Thirty-seven premature babies, who were hospitalized in the neonatal unit at Taipei Veterans General Hospital from 1997 to 2000 and had received diode laser ( $810 \mathrm{~nm}$ wavelength) treatment (Iris Medical Instruments Inc., Mountain View, CA, USA) therapy under laser indirect ophthalmoscope for threshold ROP, were identified. The setting of laser treatment was 250-300 mW at the creamy-white laser intensity, near confluence pattern, and placed to the retina avascular zone anterior to the fibrovascular ridge.

Of the 37 children with laser-treated threshold ROP, one infant who had zone I rush disease rapidly progressed to stage 5 despite photocoagulation. Unfortunately, this patient died before the age of 6 months, and this was not attributed to ROP laser treatment. Six patients were excluded from this study because they were lost to follow-up. The remaining 30 children were recruited in this study with informed parental consent. The patients were recalled at the age of 7 years to the eye clinic at Taipei Veterans General Hospital for complete ophthalmologic assessment by the clinicians (CY and AW). The following clinical parameters were recorded at each examination.

\section{Visual acuity}

The best-corrected visual acuity (BCVA) was determined by Snellen chart at $6 \mathrm{~m}$. Patients wore the glasses with the cycloplegic refraction determined by the autorefractometer and it was refined. To include all data in the statistical analysis and comparison, visual acuity was converted as the log of the minimum angle of resolution $(\log$ MAR) value, and any eye with vision less than $1 / 60$ was assigned as logMAR score of 2.0. Also for statistical purpose, when analysing the probable risk factors associated with poor visual outcome, visual acuity of $6 / 12$ or better was considered a good visual outcome, and visual acuity of $6 / 15$ or worse a poor visual outcome.

\section{Refraction}

Cycloplegic refraction of the eyes was determined with desktop computer autorefractometer (Topcon Corporation, Tokyo, Japan) after instillation of $1 \%$ cyclopentolate hydrochloride eye drops twice at a $10 \mathrm{~min}$ interval. Refractive error was converted to the spherical equivalent (SE). Myopia was divided into three categories according to its magnitude (dioptre): 0-3.0, 3.1-6.0, and >6.0 D. Those with astigmatism were classified as having errors of $0-1.5,1.6-3.0$, and >3.0 D. Children with high myopia $>6.00 \mathrm{D}$, anisometropia $\geqslant 1.5 \mathrm{D}$, or astigmatism $>3.0 \mathrm{D}$ were considered to have advanced refractive error.

\section{Structural assessment}

Indirect ophthalmoscopy was performed to detect any structural sequelae, including straightening of arcade vessels, macular distortion or dragging, macular fold, or tractional retinal detachment.

\section{Orthoptic assessment}

Cover test, prism cover test, and ocular movements were evaluated to detect any abnormality of ocular motility. Strabismus was defined as a latent symptomatic or a manifest squint, as well as patients who had received previous strabismus surgery. 


\section{Perinatal neurological events}

The presence of intraventricular haemorrhage (IVH) or periventricular leucomalacia (PVL) was documented from the record of cranial ultrasound. Any neurological sequelae, including cerebral palsy (CP), mental retardation, or history of rehabilitation were also recorded.

\section{Risk factors of poor visual outcome}

To identify and evaluate the probable risk factors associated with poor visual outcome (visual acuity 6/15 or worse) in patients with laser-treated ROP, data were analysed using $\chi^{2}$-test and Fisher's exact test (if the expected value was under 5) for the univariate analysis.

\section{Statistical analysis}

Statistical analysis of the data was performed using SPSS software (version 15.0; SPSS Inc., Chicago, IL, USA). For the purpose of comparison, the two eyes of the same patient (eg, a patient with anisometropia or strabismus) were used as independent variables. Continuous outcomes were compared using independent Student's $t$-test or Wilcoxon rank-sum test. $\chi^{2}$-Test and Fisher's exact test were used to compare categorical outcomes. A $P$ value $<0.05$ was considered statistically significant.

\section{Results}

Total 30 children with 60 eyes of threshold ROP were recruited and reviewed in this study. The mean gestational age at birth was $28.7 \pm 2.6$ weeks and the mean birth weight was $1213 \pm 302 \mathrm{~g}$. The mean follow-up period was $7.8 \pm 0.8$ years (range: $7.0-9.0$ ).

\section{Anatomical outcome}

Of the 60 laser-treated eyes, 1 eye (1.7\%; case no. 7) had macular dragging and a retinal fold involving the fovea on fundoscopy. This patient had zone I rush disease. None of the remaining eyes that were treated had any evidence of macula ectopia, disc dragging, or other sign of poor structural outcome. Overall, 59 eyes (98.3\%) had a favourable structural outcome.

\section{Visual outcome}

One patient (case no. 25) with perinatal history of severe IVH had severe cognitive impairment as a result of $\mathrm{CP}$, and was unable to cooperate with the assessment of visual function. Therefore, data on visual outcome were available on 58 eyes ( 29 patients). The detailed information of functional outcome of laser-treated eyes is shown in Table 1 . The laser-treated eyes had a mean visual acuity of $20 / 46$, with 38 eyes $(65.5 \%)$ achieving $6 / 12$ or better vision (Table 2 ). However, an unfavourable visual acuity outcome of $6 / 60$ or worse occurred in 4 eyes $(6.9 \%)$ of 3 patients. One eye in one child had an unfavourable structural outcome (macular fold) as outlined above. Three eyes of the other 2 children had advanced myopia, astigmatism, and anisometropia.

Table 1 Functional outcome of the patients with laser-treated retinopathy of prematurity

\begin{tabular}{|c|c|c|c|c|c|c|c|}
\hline \multirow[t]{2}{*}{ Patient } & \multirow[t]{2}{*}{$\begin{array}{c}G A \\
\text { (weeks) }\end{array}$} & \multirow[t]{2}{*}{$\begin{array}{l}B W \\
(g)\end{array}$} & \multirow[t]{2}{*}{ Gender } & \multicolumn{2}{|c|}{$B C V A$} & \multicolumn{2}{|c|}{$\begin{array}{l}\text { Spherical } \\
\text { equivalent }\end{array}$} \\
\hline & & & & $O D$ & OS & $O D$ & OS \\
\hline 1 & 31 & 1600 & M & $6 / 7.5$ & $6 / 12$ & -0.25 & -0.75 \\
\hline 2 & 31 & 1900 & M & $6 / 12$ & $6 / 6$ & 0.00 & -0.25 \\
\hline 3 & 34 & 1380 & M & $6 / 20$ & $6 / 12$ & -5.50 & -2.75 \\
\hline 4 & 29 & 1011 & $\mathrm{~F}$ & $6 / 12$ & $6 / 30$ & -5.00 & -8.00 \\
\hline 5 & 26 & 900 & F & $6 / 10$ & $6 / 30$ & -1.25 & -8.50 \\
\hline 6 & 26 & 760 & F & $6 / 30$ & $6 / 30$ & -14.25 & -13.75 \\
\hline $7^{\mathrm{a}}$ & 28 & 1250 & F & $1 / 60$ & $6 / 10$ & +0.75 & -7.50 \\
\hline 8 & 26 & 950 & F & $6 / 12$ & $6 / 12$ & -0.25 & +0.25 \\
\hline 9 & 30 & 1130 & F & $6 / 10$ & $6 / 7.5$ & +2.75 & +2.75 \\
\hline 10 & 27 & 1150 & F & $6 / 10$ & $6 / 10$ & -5.25 & -8.00 \\
\hline 11 & 28 & 1100 & M & $6 / 15$ & $6 / 15$ & -3.75 & -2.00 \\
\hline 12 & 32 & 1246 & M & $6 / 10$ & $6 / 7.5$ & +0.75 & +0.75 \\
\hline 13 & 34 & 1530 & $\mathrm{~F}$ & $6 / 6$ & $6 / 6$ & +0.75 & +0.50 \\
\hline 14 & 26 & 1090 & M & $6 / 15$ & $6 / 15$ & -2.50 & -1.00 \\
\hline 15 & 26 & 1230 & M & $6 / 12$ & $6 / 7.5$ & +0.75 & +0.75 \\
\hline 16 & 25 & 870 & M & $6 / 60$ & $6 / 60$ & -19.00 & -16.25 \\
\hline 17 & 25 & 900 & $\mathrm{~F}$ & $6 / 10$ & $6 / 30$ & -1.25 & -4.75 \\
\hline 18 & 28 & 920 & $\mathrm{~F}$ & $6 / 10$ & $6 / 10$ & -2.75 & -0.50 \\
\hline 19 & 26 & 650 & $\mathrm{M}$ & $6 / 7.5$ & $6 / 12$ & -2.25 & -2.75 \\
\hline 20 & 29 & 1454 & $\mathrm{~F}$ & $6 / 7.5$ & $6 / 7.5$ & -1.00 & -1.75 \\
\hline 21 & 31 & 1606 & F & $6 / 12$ & $6 / 12$ & -9.25 & -9.25 \\
\hline 22 & 29 & 1460 & F & $6 / 6$ & $6 / 6$ & +0.50 & -0.25 \\
\hline 23 & 31 & 1306 & F & $6 / 30$ & $6 / 30$ & -8.50 & -5.50 \\
\hline 24 & 30 & 1510 & $\mathrm{~F}$ & $6 / 30$ & $6 / 15$ & -10.50 & -1.75 \\
\hline 25 & 28 & 1300 & M & NA & NA & -5.50 & -7.00 \\
\hline 26 & 30 & 1618 & $\mathrm{~F}$ & $6 / 20$ & $6 / 7.5$ & -9.00 & -3.00 \\
\hline 27 & 32 & 1340 & $\mathrm{~F}$ & $6 / 12$ & $6 / 10$ & -5.75 & -4.50 \\
\hline 28 & 25 & 760 & $\mathrm{M}$ & $6 / 12$ & $6 / 12$ & -5.50 & -5.50 \\
\hline 29 & 29 & 1080 & M & $6 / 7.5$ & $6 / 7.5$ & -2.00 & -2.25 \\
\hline 30 & 29 & 1450 & M & $6 / 60$ & $6 / 15$ & -9.00 & -4.25 \\
\hline
\end{tabular}

Abbreviations: $\mathrm{GA}=$ gestational age; $\mathrm{BW}=$ body weight; $\mathrm{BCVA}=$ bestcorrected visual acuity; $\mathrm{M}=$ male; $\mathrm{F}=$ female; $\mathrm{NA}=$ not applicable as assessment of visual acuity is not possible.

apatient No 7 had a retinal fold involving the fovea of right eye.

Table 2 Refractive and visual outcomes of eyes with lasertreated threshold retinopathy of prematurity

\begin{tabular}{lc}
\hline Mean Snellen BCVA & $20 / 46$ \\
Spherical equivalent (D) & $-3.87 \pm 4.78$ \\
Myopia (D) & $3.05 \pm 3.99$ \\
Astigmatism (D) & $2.96 \pm 1.58$ \\
\hline
\end{tabular}

Abbreviations: $\mathrm{BCVA}=$ best-corrected visual acuity; $\mathrm{D}=$ dioptre. 


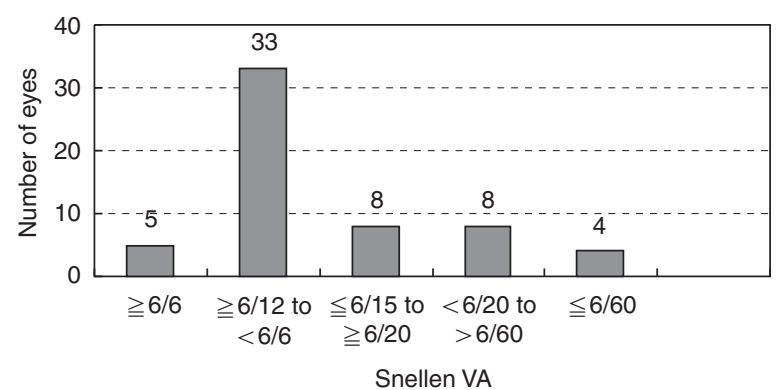

Figure 1 Visual acuity (Snellen VA) outcome in eyes with lasertreated threshold retinopathy of prematurity $(N=58)$.

These 2 children also had suffered from the perinatal neurological events of IVH. In addition, 2 eyes in these 3 children were also esotropic and amblyopic.

A moderate visual loss with BCVA $\leqslant 6 / 15$ but $>6 / 60$ was found in 16 eyes (27.6\%; Figure 1). These 16 eyes with normal fundus structure had impaired visual function associated with problems such as anisometropia, strabismus and advanced refractive error (high myopia and astigmatism).

\section{Refractive error}

The overall average refractive spherical equivalent was $-3.87 \pm 4.78 \mathrm{D}$ (range: +0.75 to -19.0 ). Of these 60 lasertreated eyes, 46 eyes $(77.0 \%)$ were myopic. The refractive status of patients with laser-treated ROP was as followings: mean myopia $3.05 \pm 3.99 \mathrm{D}$ and mean astigmatism $2.96 \pm 1.58 \mathrm{D}$ (Table 2). The distribution of refractive error was shown in Figure 2. Advanced refractive error such as high myopia $(>6.0 \mathrm{D})$ was found in 10 eyes (16.7\%), and high astigmatism (>3.0 D) in 21 eyes $(35.0 \%)$. In addition, significant anisometropia $(\geqslant 1.5 \mathrm{D})$ was also noted in 14 patients $(46.7 \%)$. None of children with high myopia had family history of pathologic myopia.

In the univariate analysis, the risk factors associated with poor visual outcome of $6 / 15$ or worse were analysed in patients with laser-treated ROP. A trend towards significantly higher risk was seen for patients with anisometropia associated with poor visual outcome $(P=0.002)$. There were no significant association with strabismus, IVH, PVL, or CP $(P=0.125,0.449,0.911$, and 0.950 , respectively).

\section{Strabismus}

Of the 30 laser-treated patients, $9(30.0 \%)$ had strabismus (with 5 cases esotropia and 4 cases exotropia). Among these patients with strabismus, the most common concomitant conditions were perinatal neurological
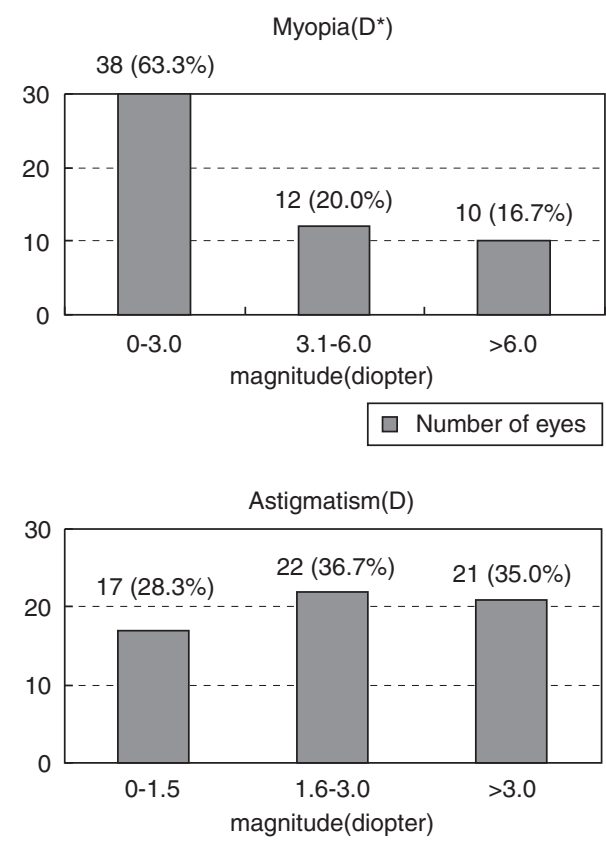

Number of eyes

Figure 2 Distribution of the refractive status (myopia and astigmatism) in eyes with laser-treated threshold retinopathy of prematurity $(N=60)$.

events (PVL or IVH) noted in six patients, anisometropia in five children, high myopia in two cases, and one case with unfavourable anatomical outcome of the macula fold. There was a statistically significant association of the presence of strabismus with PVL $(P=0.002)$ but not $\mathrm{IVH}, \mathrm{CP}$, or anisometropia $(P=0.253,0.457$, and 1.000 , respectively).

Nine patients were treated for amblyopia. Among them, strabismic amblyopia was noted in two patients, anisometropic amblyopia in four cases, and amblyopia with extremely high myopia (>10.0 D) or high astigmatism in three cases.

\section{Perinatal neurological events}

The occurrence of perinatal neurological events was noted in patients with laser-treated threshold ROP, including IVH in eight patients (26.7\%), PVL in eight cases $(26.7 \%)$, and CP in four children (13.3\%).

\section{Discussion}

Our study presented the long-term visual outcome and refractive status in children aged $\geqslant 7$ years with lasertreated threshold ROP. The majority of patients with diode laser-treated threshold ROP in this study had favourable anatomical and visual outcomes. The favourable long-term visual outcome of our report is 
similar in comparison with the findings of other investigators in literature shown in Table 3. However, among patients with good structural outcome, many patients suffered from impaired visual function on long-term follow-up. Of these 60 laser-treated eyes, 46 eyes (77.0\%) were myopic and the mean spherical equivalent was $-3.87 \mathrm{D}$. Anisometropia $(\geqslant 1.5 \mathrm{D})$ was also noted in 14 patients $(46.7 \%)$.

Additionally, strabismus and perinatal neurological events were noted in some laser-treated patients. Meanwhile, the presence of anisometropia was significantly associated with poor visual outcome in patients with laser-treated ROP.

In this study, $77.0 \%$ of the laser-treated eyes were myopic with $16.7 \%$ having more than $6.0 \mathrm{D}$ of myopia. McLoone et $\mathrm{al}^{7}$ reported the similar results with $50 \%$ of their laser-treated eyes being myopic and 35\% having more than $4.0 \mathrm{D}$ of myopia. Development of myopia is common in premature infants, and the incidence of myopia increases with increasing prematurity and severity of ROP. ${ }^{12,13}$ Quinn et al $^{14}$ reported $20.0 \%$ of verylow-birth-weight infants (less than $1251 \mathrm{~g}$ ) without undergoing cryotherapy developed myopia in the first 2 years of life, and $4.6 \%$ had high myopia ( $>5.0 \mathrm{D}$ ). In addition, both lower birth weight and severity of ROP were strong predictors of myopia and high myopia. ${ }^{14}$ The exact mechanism of myopia associated with ROP is not well understood. It is not possible in this study to conclude that laser plays a causative role of excess myopia related to scleral weakening. Various hypotheses, including anomalies of corneal diameter and curvature, shallow anterior chamber, axial length, and lens power, have been suggested..$^{12,14,15}$ Some of these abnormalities might relate to the disturbed ocular growth in infants with ROP, and high crystalline lens power is suggested to be the predominant contributing factor of myopia in eyes with ROP. ${ }^{13,16}$ Tasman et $a l^{17}$ found that patients with ROP and a high degree of myopia had a higher rate of retinal detachment in latter life. The sequelae of advanced ROP may cause problems throughout the patient's life; therefore, long-term follow-up is crucial for patients with laser-treated ROP.

Table 3 Comparison of previous studies in long-term outcomes of eyes with laser-treated retinopathy of prematurity

\begin{tabular}{lclcc}
\hline Authors & $\begin{array}{c}\text { No. of } \\
\text { eyes }\end{array}$ & Laser & $\begin{array}{c}\text { Follow-up } \\
\text { (years) }\end{array}$ & $\begin{array}{c}\text { Mean } \\
\text { BCVA }\end{array}$ \\
\hline $\begin{array}{l}\text { McLoone } \\
\text { et } \text { al }^{7}\end{array}$ & 37 & Diode & 11.0 & $20 / 47$ \\
Ng et $^{5} l^{5}$ & 23 & Argon and diode & 9.9 & $20 / 66$ \\
$\begin{array}{l}\text { Ospina } \text { et } a l^{11} \\
\text { Our study }\end{array}$ & 42 & Argon & 6.2 & $20 / 98$ \\
\hline
\end{tabular}

Abbreviation: $\mathrm{BCVA}=$ best-corrected visual acuity.
Strabismus is common after ROP regression, and is strongly associated with neurological abnormalities in premature infants. ${ }^{18-21}$ The incidence of strabismus is reported to be higher in infants with regressed ROP (34\%) in comparison with premature infants without ROP $(16 \%)$. Furthermore, the incidence of strabismus rose with the severity of ROP. ${ }^{19,20,22}$ In this study, strabismus occurred in $30.0 \%$ of the patients with lasertreated threshold ROP. Meanwhile, impaired visual acuity is more frequent among premature infants with visual pathway damage. ${ }^{23} \mathrm{O}^{\prime}$ Connor $e t a l^{24}$ found that anisometropia, high refractive error, low birth weight, $\mathrm{ROP}$, and $\mathrm{CP}$ were independently associated with the presence of strabismus. Similarly, in this study, we also demonstrate that the presence of strabismus is significantly associated with neurological insult of PVL. Strabismic amblyopia usually develops in patients with esotropia, who frequently have a fixation preference for one eye, than in patients with exotropia, who have an alternating fixation. ${ }^{25}$ Combining occlusion therapy, refractive correction and strabismus muscle surgery are successful in management of the majority of patients with ROP-associated strabismus and amblyopia. ${ }^{18}$ Eight of the nine patients with strabismus in this study achieved ocular alignment less than 10 prism dioptres of orthophoria, and two patients with amblyopia had satisfactory result after conventional amblyopic therapy.

Cases of anisometropia and astigmatism were greater in patients with regressed low-grade ROP as compared with non-ROP patients. ${ }^{19}$ Quinn $e t ~ a l^{14}$ reported a $4.8 \%$ incidence of anisometropia in 1548 ROP infants. The increased incidence of anisometropia in resolved ROP is not unexpected, because many cases of regressed ROP are asymmetric regarding the final peripheral retinal fibrosis. This asymmetry may contribute to the occurrence of anisometropia. ${ }^{18,19}$ In this study, the presence of anisometropia and a higher degree of astigmatism are also found in laser-treated ROP. We also demonstrate that significant anisometropia ( $\geqslant 1.5 \mathrm{D}$ ) is often associated with impaired visual function in patients with lasertreated ROP. Unilateral high myopia ( $>6.0 \mathrm{D}$ ) often results in anisometropic amblyopia in our study. Children with anisometropic amblyopia without significant strabismus should have spectacle correction of the full refractive error as determined with cycloplegia. Successful treatment of anisometropic amblyopia has been reported with spectacle alone ${ }^{26,27}$ Contact lens is an alternative management of high anisometropic amblyopia if children develop unacceptable aniseikonia with spectacle correction. ${ }^{28}$ If amblyopia persist after glasses correction, the next step consists of occlusion or penalization of non-amblyopic eye. 
In addition to the structural outcome of the retina, associated ocular dysfunction, such as refractive disorder, are key factors of the visual outcome in children with regressed ROP. McLoone et $a^{7}$ reported that $73.0 \%$ of eyes achieved $6 / 12$ or better vision and $27.0 \%$ (10 eyes) had reduced visual acuity of $6 / 15$ or worse in a study of 25 patients (43 eyes) with diode laser-treated ROP. ${ }^{7}$ Among the 10 eyes with reduced vision, only 3 eyes had abnormal structural outcome whereas the other eyes had unfavourable visual outcomes due to strabismus, amblyopia, and nystagmus. ${ }^{7}$ In this study, we found impaired visual acuity of $6 / 15$ or worse in 20 eyes $(34.5 \%)$, but only 1 eye experienced an unfavourable anatomical outcome. In most eyes, impaired visual outcome is attributed to anisometropia, high myopia, high astigmatism, strabismus, and perinatal neurological events of PVL and IVH. To support this, Ospina et $a l^{11}$ reported that retinal scarring and detachment were relatively rare causes of visual morbidity unlike strabismus, amblyopia, and neurological sequelae, which were important causes of impaired visual function, in a 5-year follow-up study after argon laser treatment for threshold ROP. Therefore, we suggest that premature children with laser-treated ROP should undergo regular follow-up by paediatric ophthalmologists for early identification of risk factors associated with poor visual outcome during the golden period of ocular development.

Some potential limitations of our study include its retrospective and non-randomized study design. An ideal control group of this study should recruit patients with threshold ROP but without laser photocoagulation therapy. However, the CRYO-ROP study has confirmed the long-term benefit of retinal ablation by cryotherapy on acute threshold $\mathrm{ROP},{ }^{2}$ and the design of such a control study would be unethical. In the future, a prospective clinical trial is required to determine the long-term visual outcomes of threshold and subthreshold ROP after conventional laser or other early therapy.

In conclusion, the majority of patients with diode lasertreated threshold ROP in this study had favourable anatomical and visual outcomes. However, anisometropia, advanced refractive error and strabismus are the important causes of impaired visual function in patients with laser-treated threshold ROP. These conditions obviously lead to an increased risk of amblyopia. Longterm regular follow-up is very important in patients with regressed retinopathy for early detection and timely treatment of these treatable ocular morbidities during the childhood period. Furthermore, the goal of future research should be directed towards reducing the occurrence of blindness from the sequelae of active ROP, as well as to eliminate and treat these associated ocular morbidities of threshold ROP.

\section{Acknowledgements}

This study was supported in part by grants from Taipei Veterans General Hospital (Grant No: V97C1-164), Taiwan

This work was presented in part at the American Academy of Ophthalmology Annual Meeting, New Orleans, LA, November 2007.

\section{References}

1 Cryotherapy for Retinopathy of Prematurity Cooperative Group. Multicenter trial of cryotherapy for retinopathy of prematurity. Three-month outcome. Arch Ophthalmol 1990 108: 195-204.

2 Cryotherapy for Retinopathy of Prematurity Cooperative Group. Multicenter trial of cryotherapy for retinopathy of prematurity: ophthalmological outcome at 10 years. Arch Ophthalmol 2001; 119: 1110-1118.

3 Hunter DG, Repka MX. Diode laser photocoagulation for threshold retinopathy of prematurity. A randomized study. Ophthalmology 1993; 100: 238-244.

4 Laser ROP Study Group. Laser therapy for retinopathy of prematurity. Arch Ophthalmol 1994; 112: 154-156.

5 Ng EY, Connolly BP, McNamara JA, Regillo CD, Vander JF, Tasman W. A comparison of laser photocoagulation with cryotherapy for threshold retinopathy of prematurity at 10 years: part 1 . Visual function and structural outcome. Ophthalmology 2002; 109: 928-934, discussion 935.

6 Early Treatment for Retinopathy of Prematurity Cooperative Group. Revised indications for the treatment of retinopathy of prematurity: results of the early treatment for retinopathy of prematurity randomized trial. Arch Ophthalmol 2003; 121: 1684-1696.

7 McLoone E, O'Keefe M, McLoone S, Lanigan B. Long term functional and structural outcomes of laser therapy for retinopathy of prematurity. Br J Ophthalmol 2006; 90: 754-759.

8 Yang CS, Chen SJ, Lee FL, Hsu WM, Liu JH. Retinopathy of prematurity: screening, incidence and risk factors analysis. J Chin Med Assoc 2001; 64: 706-712.

9 Yang CS, Chen SJ, Lee FL, Hsu WM, Liu JH. Clinical survey of retinopathy of prematurity. Taiwan J Ophthalmol 2002; 41: 51-58.

10 The Committee for the Classification of Retinopathy of Prematurity. An international classification of retinopathy of prematurity. Arch Ophthalmol 1984; 102: 1130-1134.

11 Ospina LH, Lyons CJ, Matsuba C, Jan J, McCormick AQ. Argon laser photocoagulation for retinopathy of prematurity: long-term outcome. Eye 2005; 19: 1213-1218.

12 McLoone EM, O'Keefe M, McLoone SF, Lanigan BM. Longterm refractive and biometric outcomes following diode laser therapy for retinopathy of prematurity. J AAPOS 2006; 10: 454-459.

13 Gordon RA, Donzis PB. Myopia associated with retinopathy of prematurity. Ophthalmology 1986; 93: 1593-1598.

14 Quinn GE, Dobson V, Repka MX, Reynolds J, Kivlin J, Davis B et al. Development of myopia in infants with birth weights less than 1251 grams. The Cryotherapy for Retinopathy of Prematurity Cooperative Group. Ophthalmology 1992; 99: 329-340. 
15 Cryotherapy for Retinopathy of Prematurity Cooperative Group. The natural ocular outcome of premature birth and retinopathy. Status at 1 year. Arch Ophthalmol 1994; 112 903-912.

16 Connolly BP, Ng EY, McNamara JA, Regillo CD, Vander JF, Tasman W. A comparison of laser photocoagulation with cryotherapy for threshold retinopathy of prematurity at 10 years: part 2. Refractive outcome. Ophthalmology 2002; 109: 936-941.

17 Tasman W. Late complications of retrolental fibroplasia. Ophthalmology 1979; 86: 1724-1740.

18 Kushner BJ. Strabismus and amblyopia associated with regressed retinopathy of prematurity. Arch Ophthalmol 1982; 100: 256-261.

19 Schaffer DB, Quinn GE, Johnson L. Sequelae of arrested mild retinopathy of prematurity. Arch Ophthalmol 1984; 102: 373-376.

20 Sahni J, Subhedar NV, Clark D. Treated threshold stage 3 versus spontaneously regressed subthreshold stage 3 retinopathy of prematurity: a study of motility, refractive, and anatomical outcomes at 6 months and 36 months. Br J Ophthalmol 2005; 89: 154-159.

21 Gibson NA, Fielder AR, Trounce JQ, Levene MI. Ophthalmic findings in infants of very low birthweight. Dev Med Child Neurol 1990; 32: 7-13.
22 Laws D, Shaw DE, Robinson J, Jones HS, Ng YK, Fielder AR. Retinopathy of prematurity: a prospective study. Review at six months. Eye 1992; 6: 477-483.

23 Pike MG, Holmstrom G, de Vries LS, Pennock JM, Drew KJ, Sonksen PM et al. Patterns of visual impairment associated with lesions of the preterm infant brain. Dev Med Child Neurol 1994; 36: 849-862.

24 O'Connor AR, Stephenson TJ, Johnson A, Tobin MJ, Ratib S, Fielder AR. Strabismus in children of birth weight less than 1701 g. Arch Ophthalmol 2002; 120: 767-773.

25 Von Noorden GK, Dowling JE. Experimental amblyopia in monkeys. II. Behavioral studies in strabismic amblyopia. Arch Ophthalmol 1970; 84: 215-220.

26 Cotter SA, Edwards AR, Wallace DK, Beck RW, Arnold RW, et al., Pediatric Eye Disease Investigator Group. Treatment of anisometropic amblyopia in children with refractive correction. Ophthalmology 2006; 113(6): 893-903.

27 Steele AL, Bradfield YS, Kushner BJ, France TD, Struck MC, Gangnon RE. Successful treatment of anisometropic amblyopia with spectacles alone. J AAPOS 2006; 10(1): 37-43.

28 Roberts CJ, Adams GG. Contact lenses in the management of high anisometropic amblyopia. Eye 2002; 16(5): 577-579. 